\title{
A representação emancipada ${ }^{1}$
}

A constituição do teatro é completamente contraditória. Esta é uma evidência que muitas vezes nós perdemos de vista. Fundado na mimese, o teatro faz da ação uma ilusão e também, por vezes, da ilusão uma ação. Seu funcionamento repousa igualmente sobre o texto e sobre a cena. O texto, por definição, é duradouro e se oferece à releitura e à repetição (ele conta); a cena é efêmera e reproduz sem nunca repetir de modo completamente idêntico (ela representa). A união entre texto e cena, o objetivo do teatro, é de certa forma antinatural. Ela não se realiza a não ser através de acordos, equilíbrios parciais e instáveis. Às vezes, é a cena que está subordinada ao texto: como o quer uma certa tradição no Ocidente, mas essa tradição é no fim das contas recente (não vai além do século XVII) e está longe de ser válida para todas as formas de teatro. As práticas populares, das farsas aos espetáculos de variedades, por exemplo, a ignoram. Algumas vezes o texto está submetido à cena, no sentido amplo da palavra, e esta é a regra em todas as tradições não-europeias.

Se o teatro antigo se propõe a unidade e reivindica a dignidade enquanto arte, o teatro moderno ocidental não é imune a essas contradições. Ele as torna ainda mais manifestas, as evidencia e não cessa de se interrogar sobre elas. Talvez extraia dessas contradições a sua identidade.

\section{Um teatro unificado}

O teatro moderno nasceu, no final do século XIX, do advento do encenador como mestre da cena. É certo que este sucedeu o diretor de palco, mas ele não é um simples herdeiro. $\mathrm{O}$ diretor de palco verificava e coordenava os elementos da representação: ele

\footnotetext{
1 Esta é a tradução do último capítulo da obra La représentation émancipée de Bernard Dort, publicada pela editora Actes Sud em 1988. A revista Sala Preta agradece a editora por ceder gratuitamente os direitos para a tradução e publicação do ensaio. Tradução Me. Rafaella Uhiara 
era somente o responsável por manter uma determinada ordem já estabelecida, independentemente dele. O encenador não apenas continua a organizar esses elementos, como ele também os projeta e pensa de antemão em sua organização - ele será o responsável se não por criá-los, ao menos por lhes dar forma. Ele age em um ponto anterior ao que operava o diretor de palco. Ele não reproduz: produz. Assim, ele não se enquadra mais na categoria de executor: ele se torna autor do espetáculo.

Uma outra mutação veio a seguir. Elaborado pelo encenador, o espetáculo tende a se estabelecer e ganhar autonomia. Algumas vezes ele chega a ser escrito de antemão: Otomar Krejca, por exemplo, redige, antes dos ensaios, um projeto de encenação bastante detalhado que constitui a partitura do espetáculo. O texto dramático propriamente dito se vê, desta forma, duplicado, sustentado ou suplantado por um novo texto: o texto cênico.

Os grandes teóricos do fim do século XIX sonham com um teatro "unificado". Já em 1850-1851, Richard Wagner precisa sua concepção da "obra de arte do futuro": é a Gesamtkunstwerk ou a "obra de arte comum"3. Esta seria o produto de uma união das artes agindo comumente sobre um público comum: a tríade poesia, música e mímica à qual se une a arquitetura e a pintura (BABLET, 1965, P.58). Conclusão de Wagner: a obra de arte comum suprema é o drama: dada a sua perfeição possível, ele só pode existir se todas as artes estão contidas nele em sua maior perfeição (Ibid.) ${ }^{4}$. Cinquenta anos mais tarde (1905), Gordon Craig corrige e radicaliza a ideia de Wagner. Para ele, o teatro não pode ser a arte suprema que resulta da ação conjunta de várias artes, pois dessa maneira ele estaria estreitamente subordinado a elas. A obra de arte pode resultar apenas da atividade criativa de um artista único (Ibid. P. 287). E explicita, em um texto, desde então, muitas vezes citado:

\begin{abstract}
Os elementos que o artista do futuro teatro usará para compor suas obras de arte são: o movimento, o cenário, a voz. Não é simples? Por movimento, deve se entender o gesto e a dança, que são a prosa e poesia do movimento. Por cenário, tudo o que pode ser visto, tanto os figurinos e a iluminação quanto o cenário em si. Por voz, as palavras ditas ou cantadas em oposição às falas escritas; pois as falas escritas para serem lidas e as falas escritas para serem faladas são de duas ordens completamente distintas. (CRAIG, 1953, P.141)
\end{abstract}

\footnotetext{
3 (Nota da tradutora) "CEuvre d'art commune". Vale indicar que a tradução mais utilizada para o termo alemão Gesamtkunstwerk em francês é "œuvre d'art totale" ("obra de arte total").

4 Cf. Richard Wagner (L'CEuvre d'art de l'avenir, in : CEuvres en prose, vol. III, trad. de J.-G. Prodhomme et Dr Phil. F. Holl, Delagrave, Paris, 1907, p. 216), citado por Denis Bablet, ibid.
} 


\section{Uma vitória}

Assim, se trava um combate por um teatro unificado ou reunificado, no qual o texto e a cena, fundidos em uma espécie de metatexto, tornam-se um. Este combate marca toda a atividade teatral do século XX. Aparentemente, quem sai vitorioso é o encenador. Como constatava, já em 1946, Jean Vilar, um pouco suspeito de condescendência (vale lembrar que ele queria ser intitulado simplesmente como "diretor de palco" e assinava seus espetáculos "direção de palco de Jean Vilar"), os verdadeiros criadores dramáticos destes últimos trinta anos não são os autores, mas os encenadores. [e acrescentou] Escrevo isso sem nenhum contentamento (VILAR, 1955, P.71) . Mas esta não é uma vitória pírrica?

Ela é, talvez, absoluta demais. Não só o encenador tem dominado, sob sua lei, os outros criadores da cena, como também os isolou e, por vezes, os reduziu à servidão. Os grupos ou companhias de teatro são cada vez menos numerosos (há também razões econômicas para isso). Os atores devem se contentar em ser apenas dóceis executores. Craig previa: o artista de teatro só será capaz de realizar uma obra de arte verdadeira se ele utilizar seus materiais no estado bruto (BABLET, 1965, p. 288). De fato, o encenador transformou seus colaboradores em fornecedores de "materiais em estado bruto". Ele sonhou com atores que fossem somente marionetes: nada além de um corpo e uma voz para ele brincar a seu critério. Melhor ainda: ele assumiu todas as outras funções. Ele se tornou seu próprio cenógrafo e começou a escrever ou reescrever o texto.

Neste sentido, o caso de Roger Planchon é exemplar. Ele partiu de um projeto brechtiano (ou seja, com base em um pensamento dramatúrgico), mas, fascinado por Bob Wilson e pelo "teatro de imagens", ele chegou a realizar espetáculos que encenam, mais do que um texto, uma totalidade: toda uma vida, com A.A., uma colagem de fragmentos de Arthur Adamov; toda uma época, com Folies bourgeoises, reunião de cenas de peças publicadas em La Petite illustration às vésperas da Primeira Guerra; ou ainda a totalidade de um teatro, neste caso o teatro clássico francês, com seu recente díptico Dom Juan-Athalie... Planchon pode até não mudar uma palavra do texto (ele cria interpolações, desloca ou repete certas passagens ou frases), mas ele não atua menos enquanto autor: o intertexto, ou seja, o projeto do espetáculo, conta mais do que o texto original. 
Além disso, os encenadores passaram a dirigir a maior parte das empresas e instituições teatrais, reunindo tudo em suas mãos. O slogan, divulgado em maio de 1968 pelo o Comitê Permanente dos Diretores de Teatro Populares e das Casas de Cultura reflete uma vontade que pairava no ar: "Poder aos criadores". A aliança das duas palavras, criação e poder, é notável. Não contente em reivindicar artisticamente o status de criador, tal como ele tomou forma no século XIX, o encenador ainda exige que a sociedade (particularmente o Estado) reconheça seu direito e the dê os meios para perpetuá-lo. Ele não quer mais ser somente esse autor elevado ao quadrado, esse "artista do teatro" profetizado por Craig, ele aspira a um reinado supremo.

Ao mesmo tempo, mas com algum atraso, se desenvolveu uma nova reflexão teórica sobre o teatro. A representação passou a não ser mais considerada como uma tradução do texto ou como uma inscrição deste em uma realidade cênica regida pela tradição ou pela imitação. A noção de montagem foi substituída, como dissemos, pela de escrita cênica. Recorreu-se ao conceito de signo. Encenar era converter em signos (PAVIS, 1976, P. 137). Assim, a representação era considerada como um conjunto, ou mesmo um sistema de signos (ou uma reunião de diversos sistemas de signos) que convinha inventariar. Certamente, tais análises permitiram entender melhor o fato teatral e colocaram de lado a intimidação pelo texto, que era a regra de todos os estudos universitários em teatro, reabilitando a cena. Estas análises também reestabeleceram uma relação de intercâmbio, de reflexão mútua entre teoria e prática. Não estariam levando em conta, na teoria, a grande mudança que tinha afetado essa prática? Tais Análises aumentaram o desejo de unificação do teatro como ele foi expresso, por exemplo, em Craig, dotando de um valor normativo o que era apenas um fenômeno histórico.

\section{Uma emancipação}

Talvez seja tempo de voltar a esse tema, não para negar o encenador e seu papel no espetáculo, mas para devolver o lugar aos seus outros membros e para questionar a concepção de teatro como arte unificada, no modelo da literatura ou das artes plásticas. Uma crítica de Wagner e Craig é necessária e uma nova definição da representação teatral que, ao invés de reunir, de modo estático, signos ou um metatexto, o considere enquanto um processo dinâmico que acontece no curso do tempo e que é efetivamente produzido pelo ator. 
A prática ultrapassou novamente da teoria. Eu não falo somente da contestação do encenador tirano e castrador, formulada com força e ingenuidade por alguns atores, por volta de 1968, se tornando palavra de ordem, moda. Uma outra transformação, mais ampla e mais profunda, está afetando o teatro. $\mathrm{O}$ advento do encenador e a consideração da representação como um lugar de significação (não como uma tradução ou decoração de um texto) constituiram, sem dúvida, apenas uma primeira fase. Constatamos hoje uma emancipação gradual dos elementos da representação teatral e observamos uma mudança estrutural: a renúncia à unidade orgânica ordenada a priori e o reconhecimento do fato teatral enquanto polifonia significante, aberta para o espectador.

\section{As metamorfoses do espaço}

Tomando como exemplo a evolução do espaço cênico, durante pelo menos dois séculos, um sistema unificado tinha a força de uma lei: o palco italiano propõe um espaço regrado que se organiza em função de apresentações convencionais (no teatro clássico, as áreas são reduzidas em número e possuem funções idênticas em espetáculos muito diferentes ${ }^{5}$ ), podendo ser mais ou menos decorado e com cenários mais ou menos apropriados. Posteriormente - e isso coincidiu com a chegada da encenação - este espaço se diversifica: o lugar se tornou um ambiente e, cada obra, pedia para sua representação uma organização cênica própria. Destaco que para Antoine antes de passar à montagem propriamente dita, era necessário estabelecer este ambiente, sem levar em conta os personagens ou a ação, porque é o meio que determina os movimentos dos personagens e não os movimentos dos personagens que determinam o meio [Antoine adicionava] Essa frase simples não parece dizer nada demais; no entanto é esse o segredo da impressão de novidade no início das experimentações do Théâtre Libre ${ }^{6}$. Mas da noção de ambiente concebido para cada obra, como um dado homogêneo e determinante, passou-se rapidamente, com ajuda das técnicas cênicas, à noção de lugar polivalente, transformável à vontade e sob os olhos do espectador ( me refiro especialmente aos cenários de Josef Svoboda). Desde

\footnotetext{
5 Cf. por exemplo, a análise de dois compartimentos do sistema cenográfico do teatro francês no século XVII por Jean-Pierre Ryngaert: "A masmorra e o palácio no cenário simultâneo segundo Mahelot. Estudo do funcionamento de dois espaços antagônicos", em Les voies de la création théâtrale, tomo VIII, estudos reunidos e apresentados por Élie Konigson, Éditions du C.N.R.S., 1980.

6 Cf. André Antoine, "Causerie sur la mise en scène", La revue de Paris, 1 de abril de 1903.
} 
então, o espaço não é mais uma simples moldura ou recipiente: ele atua no espetáculo em conjunto com os outros elementos deste. Se pode falar até mesmo em 'partituras espaciais' e considerar o espaço como um elemento dramaturgicamente ativo. Além disso, o espaço cênico transbordou do palco: ele passou a englobar todo o espaço do teatro, sala ou lugar onde se dá a representação. Fez-se necessário, novamente e para cada espetáculo, redefini-lo e quase que construí-lo previamente. Grotowski observou que o primeiro ato de qualquer encenação servia para separar o lugar da cena e o lugar dos espectadores. Para cada um de seus espetáculos, essa divisão se fazia de modo diferente: da interpenetração desses dois espaços em Akropolis à sua separação radical, pelo fechamento e desnivelação, em Le Prince Constant..., e isso era fundamental para a montagem. Atualmente, conhecemos bem uma outra modalidade de existência do espaço teatral na representação. Me refiro aos "espetáculos de percurso" ou, mais amplamente, ao "teatro ambiental" (environment theater, Schechner), ao "teatro da materialidade". Nestes, o lugar (frequentemente não um teatro, mas um edifício ou até uma paisagem que tem uma identidade e uma história alheias ao texto e mesmo à toda atividade lúdica) não é escolhido para responder a uma idéia preconcebida ou a certas virtualidades do texto e também não é construído ou utilizado para dar conta disso. O espaço é um elemento autônomo e durável da representação que participa da encenação da mesma forma que o texto (ou sua ausência), as mímicas, os movimentos e a declamação dos atores. Ele traz sua identidade, sua história e sua carga de significados. Texto e cena se interferem mutuamente: eles não estão a serviço um do outro, eles não se anulam. Além disso, o lugar, mais que a cena, engloba, frequentemente, até o espectador.

Quando Klaus Michael Grüber escolheu para Hyperion de Hölderlin o Estádio Olímpico de Berlim (1977), ele não viu esse espaço como um cenário apropriado para a ficção da obra: o estádio e o "romance" de Hölderlin admitem, de fato, um referente comum, a Grécia, mas a Grécia hölderliniana não tem nada a ver com as Olimpíadas nazistas de 1936. Ele também não o trata como um espaço funcional: o estádio tem vinte mil lugares, mas Grüber agrupa ali apenas uma centena de espectadores, em um pequeno estrado, fora das arquibancadas. Nessa arena desproporcional, ele instala também a fachada de uma estação berlinense destruída durante a guerra, um estande de linguiças (que existe nos dias de hoje), algumas barracas, etc. Como outros elementos de uma colagem heteróclita, misturando épocas e dimensões. $\mathrm{O}$ 
espetáculo foi apresentado nas noites frias de inverno: Hyperion é rebatizado Winterreise (viagem de inverno) - mudança de título que move o foco do texto para o lugar e tempo da representação, evocando, ao mesmo tempo, o romantismo e a epopéia do solitário schubertiano. E essa Winterreise aparece como um quebra-cabeça da Alemanha e de suas faces contrastadas. É o espectador, em transe por causa do frio, que deve viver essa confrontação entre um lugar e um texto - entre a materialidade compósita desse lugar e a ficção preponderante de Hyperion ${ }^{7}$.

Perdemos as contras de quantas tentativas existem atualmente. Certamente, às vezes elas se transformam em "som e luz": nada mais tentador e vão do que apresentar um texto em um lugar mais ou menos histórico. Mas, em seu princípio, elas são indício de uma transformação decisiva: o espaço não ilustra mais, nem oferece mais áreas organizadas para um determinado tipo de teatro. Ele entra na representação como um elemento autônomo que tem sua função e significado próprios - da mesma forma que o texto ou os atores.

\section{Um combate}

A afirmação da encenação nos trouxe à consciência o papel significativo dos elementos da representação. Inicialmente o encenador foi o único a decidir sobre sua organização semântica. Agora os outros criadores do teatro reivindicam uma responsabilidade paralela e uma relativa autonomia. Texto, espaço, interpretação se emancipam.

Assim se esboça uma nova concepção da representação. Ela não pretende mais uma fusão ou uma união das artes. Ela aposta, ao contrário, em sua independência dentro do espetáculo. Brecht gostava de falar sobre as "artes-irmãs" (em alemão: Schwesterkunste) que fazem o teatro. Reforçado por seu privilégio de autor e encenador do Berliner Ensemble, ele sacrificou, sem dúvida, a independência dessas artes-irmãs em prol de uma concepção dramatúrgica unitária das obras que ele montou. Mas sua lição vai mais longe do que a sua prática. Ele desenha a imagem de uma representação não-unificada, na qual diversos elementos entrariam em colaboração, até mesmo em rivalidade, ao invés de se anular para construção de um sentido comum. Deste modo, o espectador poderia escolher preencher as lacunas ou apagar os excessos de uma tal polifonia. Bertolt Brecht que seria, portanto, a pedra angular da representação, sempre

7 Vale lembrar também que essa Viagem de inverno se deu no fim de 1977, em um momento em que o terrorismo do grupo Baader-Meinhof (a fração alemã do Exército Vermelho) estava em plena atividade. Um momento de crise de identidade alemã, segundo os intelectuais de esquerda. 
quis fundamentá-la, não em si, mas no que está fora: o lugar e a reflexão do espectador. Evocando o trabalho atual de Robert Wilson, Heiner Müller diz o mesmo:

O mais importante é que Bob Wilson seja contra a interpretação [no sentido
de leitura]. Todos os elementos de seu teatro são iguais. O texto, a luz, a
coreografia, tudo tem a mesma importância. Frequentemente na Europa, e
na Alemanha, a interpretação subsume o teatro e o texto se vê reduzido. Em
Bob Wilson, a interpretação é um trabalho que o espectador deve fazer. Seu
teatro é, portanto, mais rico e os textos podem existir livremente ${ }^{8}$

Tal concepção, que se opõe à visão unitária de Wagner ou de Craig, se pode dizer agonística. Ela supõe um combate (pacífico, é claro) pelo sentido - combate em que o espectador é, por fim, o juiz. Ela pondera, no jogo cênico e no tempo, esses dados fundamentais de toda experiência teatral. Se encenar é converter em signos, atuar é deslocar esses signos, estabelecendo, em um espaço e tempo definidos, o movimento, ou mesmo, a deriva, desses signos.

\section{O espectador em jogo}

Uma vez em cena, um objeto não é mais ele mesmo: ele passa a significar. Jean Genet, por exemplo, excluía a possibilidade de se acender um cigarro em cena, não por medo do fogo, mas porque uma chama de fósforo na plateia ou em outro lugar é a mesma que no palco. Deve-se evitar" (GENET, 1966, P. 47). Seu valor de uso é retransmitido e, algumas vezes, apagado por seu valor semântico. Todavia, importa menos o que ele significa do que sua maneira de significar e o processo de significações que ele alimenta durante todo o espetáculo. Que o taco de Arlequim seja também um falo, isso merece atenção, mas o que faz a riqueza e, arrisquemos a palavra, a teatralidade desse objeto, é precisamente que ele é, ao mesmo tempo, o atributo de um personagem (o taco faz referência a Arlequim), um objeto utilitário (Arlequim se serve dele para se defender, para bater em seu inferiores ou iguais para obter o que comer) e também um falo (ele manifesta seu apetite sexual). O prazer do espectador nasce, portanto, da manipulação desse objeto e da constante transgressão de seu significado através do lúdico.

Nesta perspectiva, o ator aparece tanto como um destruidor e como um construtor de signos. Em cena, ele se torna, sem dúvida, um personagem ou uma figura. Mas essa incarnação ou fabricação nunca é completa. Por trás do personagem, sempre há o ator. No Paradoxo sobre o comediante, Diderot sugeria que o bom ator justa-

8 Cf. "Rencontre avec le dramaturge Heiner Müller: la méchanceté et de désordre", discursos reunidos por Olivier Schmitt em Le Monde, 24 de fevereiro de 1988. 
mente por não ser nada, ninguém, pode ser tudo, os personagens mais diversos. Nós podemos inverter essa proposição: é porque ele permanece sempre ele mesmo, que ele se presta a vários personagens, sem nunca perder, que o ator é bom. Ao mesmo tempo que ele está prestes a dissolver na ficção cênica, seu corpo e sua voz estão lá para nos lembrar que ele permanece irredutível a qualquer metamorfose completa.

Assim, a questão "texto e cena" se mostra pouco pertinente. Não se trata mais de saber qual elemento vai prevalecer sobre o outro (o texto ou a cena). A relação entre eles pode nem mesmo ser pensada em termos de união ou subordinação. É uma competição, uma contradição que se revela diante de nós, espectadores. Sendo assim, a teatralidade não é apenas essa "espessura de signos" da qual nos falou Roland Barthes. Ela é também o deslocamento desses signos, sua combinação impossível, seu confronto sob o olhar do espectador desta representação emancipada.

Em tal prática, o encenador perde sua soberania. Isso não significa um retorno ao status quo anterior, a um teatro de atores ou um teatro de texto. A mutação que ocorreu no início do século XX não se anulou: pelo contrário, ela se prolongou e, possivelmente, se completou. Através da tomada do poder pelo encenador, a representação tinha conquistado sua independência e seu status. Atualmente, pela emancipação progressiva dos seus diferentes componentes, a representação se abre para a ativação do espectador e se reconecta com o que é talvez a vocação do teatro: não de encenar um texto ou organizar um espetáculo, mas de ser uma crítica em processo de significação. A interpretação reencontra todo o seu poder. Enquanto construção, a teatralidade é o questionamento do sentido.

\section{Referências Bibliográficas}

BABLET, Denis. Esthétique générale du décor de théâtre de 1870 à 1914. Paris: Éditions du C.N.R.S, 1965.

CRAIG, Edward Gordon. De l'Art du théâtre. Paris: Éditions Lieutier/Librairie théâtrale, 1953.

DIDEROT, Denis. Paradoxo sobre o comediante. São Paulo: Abril, 1973.

GENET, Jean. Lettres à Roger Blin. Paris: Gallimard, 1966.

PAVIS, Patrice. Problèmes de sémiologie théâtrale. Montréal: Presses de I'Université du Québec, 1976.

VILAR, Jean. "IV: Le metteur en scène et l'œuvre dramatique", in: De la tradition théâtrale. Paris: L'Arche, 1955. 